\section{Análise de siłuação de Relações Públicas na mídia}

\section{Roberto Porto Simões}

Dr. Prof. do Programa de Pós-grad. da FAMECOS/PU-

\section{Introdução}

AlÉM DO TÍTUlO EXPRESSO formalmente ao lado, este artigo poderia ter os títulos de:

(1) Uma técnica para a elaboração do clipping;

(2) A análise de conteúdo qualitativa com categorias a priori; ou ainda,

(3) A busca de informações para uma decisão de Relações Públicas,

sem, contudo, perder o referencial com seu conteúdo, além de demonstrar como alguns temas (clipping, análise de conteúdo, busca de informação) estão interligados ou, simplesmente, são um único.

A preferência pelo que intitula o artigo foi, somente, em razão de sua origem como um instrumento didático do ensino acadêmico na identificação de situações de Relações Públicas na mídia.

\section{Premissas teóricas e técnicas}

A atividade de Relações Públicas, exercida por um profissional, implica na existência de anterior processo de relacionamento sociopolítico entre determinada organização e seus públicos, caracterizando específico fenômeno, cuja dinamicidade estrutura-se por meio de inúmeras variáveis intervenientes, resultando bom, regular ou mau nível de relações entre os dois elementos, como assim se expressou John Cook. ${ }^{1}$

Isto permite deduzir que, quem se relaciona com os públicos, é a própria organização, por meio de sua complexidade de componentes, por tudo o que faz ou deixa de fazer (ação), implicando, previamente, decisões que vão, (ou não), ao encontro dos interesses dos públicos. Este processo corresponde à relação social em suas diversas 
dimensões da sociedade organização-público.

A atividade de Relações Públicas e, especificamente, ao profissional desta atividade cabe a gestão de uma dessas instância: a relação política.

A tarefa de administrar é realizada por meio do exercício das seguintes operações:

1. Diagnosticar o processo.

2. Prognosticar seu devir.

3. Assessorar as lideranças organizacionais quanto a decisões sobre políticas organizacionais, para evitar ou resolver os assuntos controversos e crises. Entenda-se por assuntos controversos (Issues na literatura americana de Relações Públicas) determinados temas, percebidos por um ou vários públicos como prejudiciais aos seus interesses e/ou direitos.

Enquanto que por conflito (crises para os americanos) designam-se os impasses nas decisões dos protagonistas do sistema organização - público. Normalmente, o conflito ocorre após a existência de um assunto controverso.

4. Produzir programas planejados de argumentação, para justificar e / ou promover as decisões e, conseqüentemente, as ações organizacionais.

Observe-se que a primeira responsabilidade do profissional, sendo os "olhos e ouvidos" da organização, é diagnosticar o processo, o que ele faz por meio de inúmeros métodos e técnicas de pesquisa.

A mídia, ao publicar uma notícia sobre a organização, potencializa o fenômeno de Relações Públicas, oferece dados, e quem sabe informações, para o profissional elaborar seu diagnóstico. Toda notícia da mídia contém uma situação (ou, se desejarmos, um fenômeno) de Relações Públicas entre uma organização e um ou vários públicos, podendo oferecer, ao profissional, evidências de como se encontra o processo de relacionamento político da organização com os seus públicos. Por este motivo que muitas organizações realizam o clipping. Se bem que a maioria delas o faz de maneira incompleta, com pouca utilidade para o profissio- nal e para as lideranças organiza-cionais.

A leitura espontânea não é suficiente para inferências válidas. Torna-se necessário aprofundar o nível de leitura, além das aparências, para que a leitura seja válida e generalizável.

O método que cumpre essa tarefa, existente sob enfoque qualitativo, desde há muito, é a análise de conteúdo. ${ }^{2}$

Ao método de análise de conteúdo, segundo Bardin, ${ }^{3}$ correspondem os seguintes objetivos: a ultrapassagem da incerteza e o enriquecimento da leitura.

Ora, se de outra parte, tem-se , conforme Shannon, Epstein e Goldratt, ${ }^{4}$ que informação é uma redução de incerteza, oferecida quando se obtém resposta a uma pergunta.

Se a análise de conteúdo busca a ultrapassagem da incerteza e se a informação é a redução da incerteza, logo conclui-se que a análise de conteúdo é um método de busca de informação.

Caracteriza-se como informação um dado dotado com relevância e propósito, requerendo unidade de análise, consenso de significado e medição humana.

Portanto, a informação é uma qualidade do dado, jamais o dado em si.

Além disto, quando Goldratt ${ }^{5}$ difere informação de dados e Glass \& Davidson ${ }^{6}$ distinguem informe de informação, a leitura fica enriquecida no sentido de que a busca da "agulha no palheiro" ocorre por meio do método de análise de conteúdo.

Por tudo isto, o método aqui apresentado pode ser interpretado e designado por diversos títulos, mas, em síntese, é um método de busca de informação, útil, tanto para o ensino como para a atividade profissional em uma organização.

Assim que, buscando contribuir com:

(a) o clipping;

(b) a atividade profissional na realização do diagnóstico do processo de RRPP;

(c) o ensino da atividade; e, por último, lítica,

(d) a testagem da Teoria da Função Poapresento, a seguir, um instrumen- 
to de pesquisa, implicando um método, o qual, certamente, para alguns, principalmente para aqueles que lidam com análise de conteúdo, nada contêm de novidade, mas que o considero, pelo menos, sistematizador para as quatro finalidades citadas.

Este instrumento de pesquisa surgiu quando percebi que a quase totalidade dos alunos, que chegava às minhas aulas, entendia pelo termo Relações Públicas essencialmente o designativo de um profissional com tarefas instrumentais. Esta conclusão foi alcançada após alguns anos de pesquisa, quando, na primeira aula, a fim de realizar o teste de sondagem dos conhecimentos já adquiridos, é pedido aos alunos que redijam 30 linhas sobre "O que são Relações Públicas?" A questão é genérica. O verbo está no plural concordando com o termo. O conteúdo das redações, quase sem exceção, expressava e continua expressando que se trata de um profissional (singular) que faz isto ou aquilo. Certamente que, para cumprir a meta de 30 linhas, preenchiam e preenchem o espaço com vários aspectos da natureza (mas não a definem) da atividade de Relações Públicas.

Experimente você fazer o teste. Talvez possa-se fazer um projeto integrado de pesquisa.

Comecei, então, a estruturar e utilizar o instrumento, fazendo com que os alunos, por reflexão, se dessem conta de que há um processo de relacionamento sociopolítico entre a organização e seus públicos e que é em razão dele que existe a atividade, executada por um profissional.

É óbvio que o instrumento ensina os alunos, também, a fazer o diagnóstico preliminar da situação e, indo mais além, a identificar alguns princípios da teoria que lhe esta sendo ensinada. Assim os alunos chegam ao final do semestre com uma definição mais adequada do signficado do termo Relações Públicas.

A didática do uso do instrumento consistiu, até hoje, em pedir que, em cada aula, os alunos tragam uma notícia analisada. Faço a avaliação dos trabalhos, dando-lhes nota satisfatória ou não satisfatória; a obtenção de cinco satisfatórios (por vezes, três, quando a turma ultrapassa a 30 alunos), implica a dispensa dos traballhos. Ao final do semestre, em reunião de avaliação do instrumento, pergunto: “O que vocês observaram, sentiram e concluíram desde o momento que receberam a tarefa de realizar a análise de notícias até o final do trabalho". Neste momento de avaliação tem-se, então, a percepção da aprendizagem de cada aluno e da turma. Percebe-se, claramente, a introjeção do conceito do designa-tivo Relações Públicas e sua natureza.

Este instrumento foi aperfeiçoado quando comecei a utilizá-lo no mestrado em Comunicação Social da PUCRS, com meus orientandos, ${ }^{7}$ os quais colaboraram com várias idéias.

O método consta de três módulos. O primeiro, com 20 questões, tem por objetivo identificar e organizar sistematicamente, como um check list, as variáveis básicas do fenômeno do processo de Relações Públicas. Em outras palavras: as categorias a priori. Trata-se de um auxiliar didático a fim de que nenhum ponto seja esquecido, mas, principalmente, para orientar o raciocínio e o processo decisório do aluno, ou profissional com pouca experiência, que está realizando a análise do fenômeno. O profissional experiente, certamente, poderá deixar de lado o roteiro e realizar a tarefa de análise de maneira sintética e gestáltica.

$\mathrm{O}$ segundo módulo refere-se à síntese de todas as variáveis, ou seja, visa ao diagnóstico da situação. Em outras palavras, às inferências. Observe-se que os termos utilizados pertencem à rede teórica da Função Política e não de outra teoria de Relações Públicas. Contudo, penso que os termos de qualquer outra teoria (imagem, boa vontade, integração, opinião pública, etc) poderão ser utilizados, obtendo os mesmos benefícios do diagnóstico.

O terceiro módulo compreende, única e exclusivamente, o exercício acadêmico de testagem da teoria, utilizando-se os dados obtidos por meio da situação real encontrada e 
diagnosticada nos dois módulos anteriores, procurando correlacioná-los com os conceitos e os princípios da Teoria da Função Política.

O instrumento, em anexo, descreve os três módulos, contendo as instruções, as questões e, entre parênteses, algumas proposições orientadoras das respostas.

\section{O instrumento}

Módulo I - Sistemática da análise dos dados

\section{Instruções:}

Destaque a notícia, veiculada na mídia, referente à organização, lucrativa ou não, privada ou pública (exceto órgãos governamentais - vale empresas estatais).

Cole-a em uma folha de papel ofício e, após, no anverso e verso, responda às seguintes questões:

\section{Qual é o fato?}

(Contextualize, sinteticamente, o texto, buscando as respostas para as questões da notícia: O quê ? quando ? Onde? Quando ? Como? Por quê?)

2. Qual é a dimensão de direcionamento da notícia?

(Identifique qual a intenção da notícia, de seu redator e do órgão da mídia.)

\section{Esta matéria é opinativa?}

(Diga se a notícia é apenas a descrição dos fatos ou se está impregnada da opinião de quem a redigiu.)

\section{Esta notícia consta em outros veículos?}

(Identifique se esta notícia consta em outros órgãos da mídia ou se foi somente naquele da qual foi feito o clipping.)

5. Qual a organização em foco nos acontecimentos?

(Identifique a organização envolvida no fato.)
6. Que outros fatos sobre esta organização você conhece e que estejam relacionados com este?

(Registre outros fatos conhecidos por você, seja pela mídia, ou por outras fontes de informação, que estejam relacionados direta ou indiretamente com esta notícia.)

7. Quais são os públicos (agentes com influência $)^{8}$ da organização explícitos neste fato?

(Identifique os públicos citados explicitamente na notícia.)

8. Quais os públicos não-citados, mas que, implicitamente, fazem parte do fato?

(Identique os públicos que não foram citados, mas que têm a ver com os fatos, direta ou indiretamente.)

9. Quais as prováveis causas mediatas do fato?

(Identifique quais as causas que, no passado mais distante, contribuíram para o fato e sua publicação na mídia.)

10. Quais as prováveis causas imediatas do fato?

(Identifique quais as causas recentes que geraram os fatos.)

11. Quais são os públicos afetados e que afetam diretamente os fatos?

(Cite os públicos que sofreram impactos diretos dos fatos, seja positiva ou negativamente)

12. Quais são os públicos afetados e que afetam indiretamente os fatos?

(Cite os públicos que sofreram algum tipo de impacto, positivo ou negativo, porém de maneira indireta, por meio de outros públicos ou de outras situações relacionadas.)

13. Qual a ação da organização geradora dos acontecimentos?

(Identifique qual foi a ação da organização causadora dos acontecimentos.) 
14. Como esta ação se vincula com a legitimidade da decisão organizacional?

(Identifique como essa ação vai (ou não) ao encontro dos interesses dos públicos. Com que interesses se correlaciona positivamente e com quais se correlaciona negativamente.)

15. Em face de tudo isto, como fica a credibilidade organizacional, interna e externamente?

(Diga, segundo sua análise, como fica a credibilidade da organização. Para melhor ou para pior?)

16. Qual a fase do processo do conflito iminente no sistema organização-públicos (latente ou manifesta)?

(Diga em que estágio se encontra o conflito: ainda iminente, manifesto ou já superado.)

17. Esta notícia está sob controle da organização ou foi explorada espontaneamente pela mídia?

(Diga se a notícia tem suas origens na própria organização ou foi gerada pelo jornalismo investigativo ou, ainda, por boatos.)

18. O fato insere-se somente em âmbito da micropolítica ou já atingiu o da macropolítica?

(Identifique se os fatos estão somente em âmbito da organização com seu públicos ou se já atingiu as esferas governamentais, partidárias ou internacionais.)

19. Quais as implicações desta notícia para a organização?

(Diga se a notícia é positiva ou negativa para a organização e justifique.)

20. Que pode a organização fazer em relação a esta notícia?

(Identifique o que a organização pode fazer em termos de ação e, a seguir, em discurso com relação à notícia. Qual o nível de controle da organização sobre as conseqü- ências da notícia?)

Módulo II - Síntese da análise dos dados.

Instruções:

Complete, agora, os espaços em branco, utilizando-se dos dados obtidos a partir das 20 questões anteriormente analisadas.

Trata-se de uma situação de RRPP entre a organização e os públicos:

(Redija o nome da organização e dos públicos.)

Os fatos estão a indicar um processo de prevenção, de issues ou de crises. Por que ?. que.)

(Escolha o tipo de processo e justifi-

Os fatos têm a ver com a legitimidade das decisões organizacionais porque a organização

(Diga a razão pela qual as ações organizacionais foram ao encontro ou de encontro aos interesses públicos.)

Isto é motivo para que a credibilidade da organização fique

(Diga se os fatos aumentaram ou diminuíram a credibilidade da organização.)

e que o processo de cooperação de seu (s) públicos (s) fique

(Diga se a cooperação dos públicos ficou facilitada ou dificultada.)

Módulo III - Utilização didático-científica do exercício para testagem da teoria.

(Exclusivo para situações de ensino)

Instruções:

Compare o conteúdo deste exercício com a rede teórica da Teoria da Função Política, ${ }^{9}$ concluindo, ou não, da validade desta teoria para a compreensão da dinâmica do sistema organização-públicos, ou seja, dos fenômenos da função de Relações Públicas. 
(Analise o exercício e seu conteúdo, compare suas questões e respostas com a teoria da função política e conclua da validade ou não da mesma. Diga-o em linguagem científica, evitando a linguagem do senso comum.) •

\section{Notas}

1 COOK, John. "Past and future terms, myths and premises in Public Relations" In: Public Relations Quartely. New York: Primavera, 1974.

2 BARDIN, Laurence. Análise de conteúdo. Lisboa, Edições 70, 1985. pp. 42, 21, 29.

Entenda-se por análise de conteúdo, análise qualitativa, e categorias o mesmo que Bardin:

- Designa-se sob o termo de análise de conteúdo (quantitativos ou não) um conjunto de técnicas de análise das comunicações visando obter, por procedimentos, sistemáticos e objetivos de descrição do conteúdo das mensagens, indicadores e conhecimentos relativos às condições de produção/recepção (variáveis inferidas) desta mensagem.

Por análise qualitativa:

- Na análise qualitativa é a presença ou a ausência de uma dada característica de conteúdo ou de um conjunto de características num determinado fragmento de mensagem que é tomado em consideração.

Por categorias:

- Uma espécie de gavetas ou rubricas significativas que permitem a classificação dos elementos de significação constitutivas, da mensagem. É, portanto, um método taxonômico bem concebido para satisfazer os colecionadores preocupados em introduzir uma ordem, segundo certos critérios, na desordem aparente.

3 BARDIN, L. op. cit p. 37

4 SHANNON, C. \& WEAVER, W. Teoria matemática da comunicação. Rio de Janeiro: Difel, 1975, p.53.

EPSTEIN, Isaac. Teoria da informação. São Paulo: Ática, 1986. p.35.

GOLDRATT, Eliyahu M. A sindrome do palheiro: Garimpando informação num oceano de dados. São Paulo: Educator, 1992. p. 78 .

5 GOLDRATT, E. op. cit. p. 74.

6 GLASS, Roberto R. \& DAVIDSON, Phillip B. Conheça 0 inimigo. Rio de Janeiro: Biblioteca do Exército, 1956. p. 18.

7 Ana M. Roig, Belkis C. dos Santos, Diná L. Bandeira , Eloisa M. Hexsel, Glafira Bartz, Karla M. Müller, Lea J. Senger, Maria C, Dornelles, Marisa C.Soares, Roberta F. Regner e Silvana P. Flores.

8 Acrescento aqui as idéias de MINTZBERG, Henry (El poder em la organización. Barcelona: Ariel Economia,1992) em cuja teoria o público não é receptivo e passivo. Ao contrário, pode compreender desde uma única pessoa, passando por um conjunto de pessoas, um grupo e até mesmo uma ou várias organizações que tentam influenciar e influenciam as decisões da organização em foco na busca do cumprimento da sua missão.

9 SIMÕES, Roberto P. Relações Públicas: função política. São Paulo: Summus,1995. 